\title{
Fatores de Risco e Proteção para a Prontidão Escolar
}

\author{
Risk and protection factors for school readiness
}

Factores de riesgo y protección para la prontitud escolar
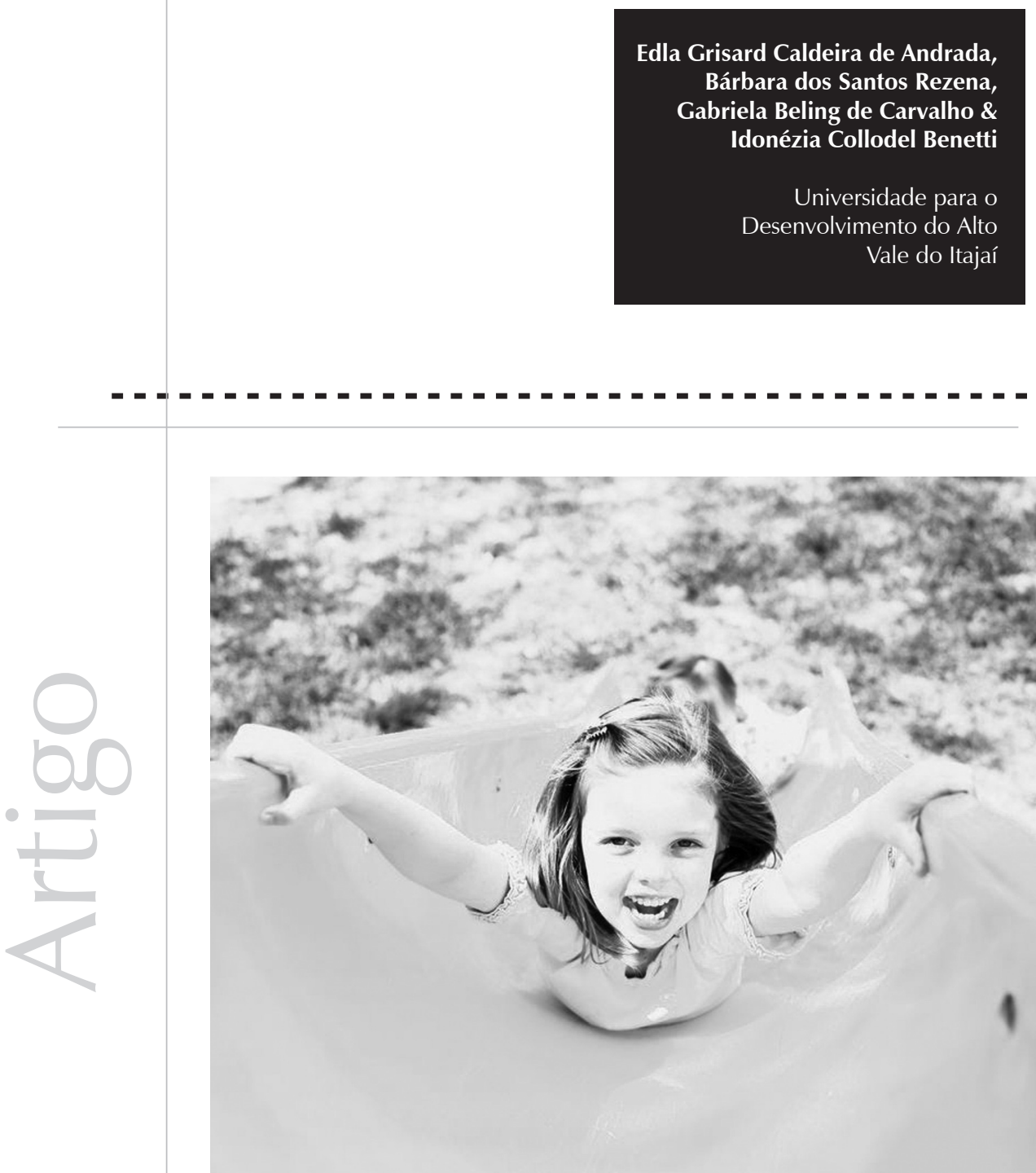
Resumo: O objetivo deste estudo foi identificar os fatores de risco e de proteção da prontidão escolar em crianças de cinco e seis anos de idade do Município de Rio do Sul/SC. Os participantes foram 130 crianças que estavam matriculadas em um dos sete centros de educação infantil públicos visitados e seus respectivos pais/mães. O suporte parental foi avaliado em quatro domínios: atividades engajadas, estímulos disponíveis, práticas parentais que promovem a ligação entre a família e a escola, e atividades previsíveis. A prontidão escolar foi avaliada através de quatro domínios, a saber, a identificação de cores e formas e formas copiadas, a descrição de figuras, a posição e o reconhecimento espacial, a identificação de números e a contagem e a identificação de letras e a escrita. A pesquisa correlacionou os estímulos presentes no microssistema familiar e a prontidão escolar das crianças. Os resultados reforçam a necessidade de as famílias se engajarem em atividades com os filhos e oferecerem estímulos materiais para que os filhos tenham maior prontidão escolar. Outros fatores que promovem a prontidão escolar são as variáveis relacionadas ao contexto familiar, como a escolaridade da mãe, a idade do pai $(p \leq 0,05)$ e a renda familiar, sendo que as crianças com escores mais altos de prontidão escolar tendem a ter mães com maior grau de escolaridade, pais mais jovens e famílias com maiores salários. Um fator de risco para a prontidão escolar a ser considerado são as famílias numerosas.

Palavras-chave: Suporte parental. Prontidão escolar. Risco. Proteção.

\begin{abstract}
The objective of this study was to identify the risk and protection factors for school readiness in children between five and six years old, from Rio do Sul/SC. The participants were 130 children who were studying in one of the seven public pre-schools visited as well as their parents. The parental support was evaluated in its four domains: engaged activities, available stimulus, parental practices that promote a link between family and school, and predictable activities. The school readiness was evaluated in four domains: the identification of colors and forms and copied forms; the description of figures, the position and the space recognition; the identification of numbers and counting, and the identification of letters and writing. The results correlated stimulus in the family micro system and the school readiness of the children. The results strengthen the necessity of the families to engage in activities with children as well as to offer material stimulus so that they can have children with higher school readiness. Other factors that promote school readiness are the variables related to family context such as the mother's level of education, the age of father and the familiar income. Children with higher school readiness tend to have mothers with higher level of education, younger parents and families with higher wages. A risk factor to school readiness to be considered is the numerous children within the family.
\end{abstract}

Keywords: Parental support. School readiness. Risk. Protection.

Resumen: El objetivo de este estudio fue identificar los factores de riesgo y de protección de la prontitud escolar en niños de cinco seis años de edad del Municipio de Río do Sul/SC. Los participantes fueron 130 niños que estaban matriculados en uno de los siete centros de educación infantil públicos visitados y sus respectivos padres/madres. El soporte parental fue evaluado en cuatro dominios: actividades relacionadas, estímulos disponibles, prácticas parentales que promueven la conexión entre la familia y la escuela, y actividades previsibles. La prontitud escolar fue evaluada a través de cuatro dominios, a saber, la identificación de colores y formas y formas copiadas, la descripción de figuras, la posición y el reconocimiento espacial, la identificación de números y las cuentas y la identificación de letras y la escritura. La pesquisa correlacionó los estímulos presentes en el microsistema familiar y la prontitud escolar de los niños. Los resultados refuerzan la necesidad de las familias de unirse en actividades con los hijos y ofrecer estímulos materiales para que los hijos tengan mayor prontitud escolar. Otros factores que promueven la prontitud escolar son las variables relacionadas al contexto familiar, como la escolaridad de la madre, la edad del padre $(p<0,05)$ y la renta familiar, siendo que los niños con puntuaciones más altos de prontitud escolar tienden a tener madres con mayor grado de escolaridad, padres más jóvenes y familias con mayores salarios. Un factor de riesgo para la prontitud escolar a ser considerado son las familias numerosas.

Palabras-clave: Soporte parental. Prontitud escolar. Riesgo. Protección. 
Este projeto de pesquisa é parte de um projeto integradocomoutras pesquisas desenvolvidas na Universidade para o Desenvolvimento do Alto Vale do Itajaí (UNIDAVI), no Curso de Graduação em Psicologia. O objetivo maior do projeto integrado é identificar as características pessoais das crianças préescolares de Rio do Sul e compará-las com as características do microssistema familiar no que se refere ao tópico suporte parental para a aprendizagem, especificamente para a prontidão escolar.

Em uma perspectiva bioecológica, para potencializar a prontidão escolar, todos os sistemas interpessoais significativos para o desenvolvimento da criança estão envolvidos, especialmente a família, a escola e o grupo de amigos. Faz-se necessário caracterizar cada um desses sistemas no contexto das condições de vida e do desenvolvimento da criança, pois existe a necessidade de programar modalidades de intervenção preventiva que incluam o sistema familiar e focalizem o processo de desenvolvimento cognitivo e os mecanismos de risco e proteção da fase escolar.

Pesquisas como as de D'Avila-Bacarji, Marturano e Elias (2005a, 2005b), Ferreira e Marturano (2002), Marturano (2006), Okano, Loureiro, Linhares e Marturano (2004) mostram que há relação entre dificuldade de aprendizagem e suporte parental, ou seja, a capacidade produtiva alcançada pela criança tem ligação com o relacionamento "pais-criança", mas há poucas pesquisas que antecipem a consolidação de uma dificuldade.

Assim, como foi objetivo da pesquisa encontrar relações entre suporte parental e prontidão escolar, buscou-se, além dessa correlação, verificar se a variável "suporte parental" se correlaciona com outras três variáveis, a saber: a) escolaridade dos pais/ cuidadores, b) remuneração mensal dos pais/ cuidadores e c) a idade dos pais/cuidadores.

Nossa intenção em identificar antecipadamente os mecanismos de risco e proteção é minimizar os impactos causados pelos riscos mediante os fatores de proteção, promovendo a prontidão escolar junto a pais e professores em futuros projetos de extensão. Essa pesquisa ainda justifica sua relevância devido ao fato de, em Rio do Sul, haver somente a tese de doutorado ${ }^{1}$ que pesquisou a prontidão escolar.

\section{Prontidão escolar}

O Censo Escolar de 2006, promovido pelo MEC - Ministério da Educação e Cultura -, revelou que, no Brasil, 7.205.013 crianças com idade entre zero a seis anos freqüentaram a escola neste ano, num fluxo bastante significativo para essa faixa etária, o que representou um crescimento de $4,4 \%$ de matrículas comparado com o ano anterior, e indicou a ampliação no atendimento escolar que atinge as crianças dessas idades (Instituto Nacional de Estudos e Pesquisas Educacionais Anísio Teixeira [INEP], 2007).

Assim, dentro da realidade em que as crianças vivenciam o espaço da escola desde muito cedo, pais, professores e educadores têm se preocupado com a questão da prontidão da criança quanto aos enfrentamentos das realidades vividas no cotidiano escolar. Nesse contexto, tornou-se questão-chave as indagações sobre quando uma criança estaria pronta para ir para a escola. Educadores e pesquisadores (Carlton \& Winsler, 1999; Meisels, 1999; Parker, Boak, Griffin, Ripple, \& Peay, 1999; Pianta \& Walsh, 1996) trazem à tona o assunto sobre o que constitui a prontidão escolar de uma criança para freqüentar um ambiente escolar ou viver um processo ensino/aprendizagem, principalmente o da leitura/alfabetização. Surgem, assim, questionamentos do tipo: o que se entende por prontidão e o que é prontidão escolar? 
Já Carlton e Winsler (1999) afirmam que, em termos práticos, a prontidão escolar pode ser observada na criança quando ela é capaz de, com sucesso, participar do currículo oferecido pela escola.
De acordo com Pianta e Walsh (1996), existem alguns fatores que emolduram a condição de uma criança que se encontra pronta para a escola. Esses fatores se constituem e são apresentados quando a criança: a) teve contato com pessoas adultas estáveis, que investiram emocionalmente nela, b) esteve exposta a um ambiente físico previsível e seguro, c) vivenciou rotinas regulares e atividades que apresentaram ritmos, d) esteve em contato com pares competentes e com materiais que estimularam sua capacidade de explorar e apreciar os objetos do mundo que a cerca bem como sua capacidade de obter um senso de controle sobre esses objetos.

Já Carlton e Winsler (1999) afirmam que, em termos práticos, a prontidão escolar pode ser observada na criança quando ela é capaz de, com sucesso, participar do currículo oferecido pela escola. Esses estudiosos apontam o fato de que o sucesso alcançado pela criança na escola se deve ao relacionamento "pais-criança" e o ambiente de suporte à aprendizagem desenvolvido no lar. Como se pode observar, de acordo com esses pesquisadores, tais características equipam a criança para que elas obtenham sucesso e tenham a tão desejada prontidão escolar.

Em harmonia com essa idéia, Bronfenbrenner (2002) enfatiza que a família é o primeiro contexto de desenvolvimento que a criança encontra e, como conseqüência, é esse meio que influenciará fortemente a trajetória inicial do desenvolvimento dessa criança. As famílias, por sua vez, estão atreladas a um contexto cultural e social, que são mais amplos e que resultam em influências diretas e indiretas nessa trajetória, em sentido geral, e na prontidão para o aprendizado, em particular, que constitui um processo de desenvolvimento visto por uma perspectiva integrada; em outras palavras, isso se traduz pelo múltiplo relacionamento entre vários fatores, de acordo com as noções do funcionamento de mesosistema proposto por esse autor.

\section{Suporte parental}

De acordo com os sistemas sociais em que a criança estiver inserida, ela pode desenvolver capacidades cognitivas em menor ou maior grau. Os principais sistemas de suporte com que a criança conta para se desenvolver e enfrentar as dificuldades são a família e a escola. A escola contribui para que a criança interaja com outras crianças, dando-lhe novas oportunidades, abrindo novos caminhos. A família contribui para que a criança desenvolva estabilidade emocional ao oferecer-lhe apoio e experiências relacionadas à cultura e à educação e ao valorizar suas atividades.

Segundo D'Avila-Bacarji et al. (2005a), a família pode oferecer às crianças três tipos de suportes: o suporte para a realização escolar, o suporte ao desenvolvimento e o suporte emocional. O suporte para a realização escolar se caracteriza pelo envolvimento dos pais na vida acadêmica dos filhos, por exemplo, em questões como a disposição de tempo dos pais e o espaço adequado para supervisão na lição de casa, o contato com o professor e as atividades diárias com horário definido.

O suporte ao desenvolvimento, para Bradley e Corwyn (2002, citados por D'Avila-Bacarji et al., 2005a), requer atividades compartilhadas pela criança e pelos pais no lar, pessoas a quem a criança possa recorrer para pedir ajuda, conselhos, oferta de brinquedos e outros materiais promotores de desenvolvimento. As atividades de lazer em que os filhos estejam incluídos, como viagens, passeios a lanchonetes, shopping centers, passeios no centro da cidade, circo, visitas a parentes e amigos, eventos na cidade e parques de diversão proporcionam atividades culturais e educacionais enriquecedoras e favorecem o desempenho cognitivo, o desempenho escolar e o aperfeiçoamento interpessoal. 


\author{
Uma relação \\ afetiva apoiadora \\ favorece o \\ desenvolvimento \\ da criança, \\ aumenta a \\ estabilidade da \\ sua base afetiva e \\ tem efeito protetor \\ na hora da \\ adversidade \\ (Boyce, 1985, \\ citado por \\ D'Ávila-Bacarji et \\ al., 2005a).
}

O suporte emocional diz respeito ao ambiente familiar acolhedor, em que não ocorre conflito na relação entre os pais, envolvimento com a Justiça, doenças ou mortes na família e práticas punitivas. Uma relação afetiva apoiadora favorece o desenvolvimento da criança, aumenta a estabilidade da sua base afetiva e tem efeito protetor na hora da adversidade (Boyce, 1985, citado por D'Ávila-Bacarji et al., 2005a). Dessa forma, o suporte parental é considerado um fator de risco quando a família apresenta menos recursos, como brinquedos, jogos, livros, entre outros, e maior número de adversidades, pois isso afeta o desenvolvimento cognitivo da criança (D'Avila-Bacarji et al., 2005a, 2005b; Sapienza \& Pedromônico, 2005).

\section{Modalidade de pesquisa}

A modalidade de pesquisa utilizada neste trabalho foi classificada, na literatura da área, como quantitativa-interpretativa por se caracterizar, na visão de Biasoli-Alves (1998), como uma pesquisa não somente e essencialmente quantitativa, mas que procura associar, à análise, os significados que os sujeitos participantes atribuem a um determinado fenômeno, suas interações (ações, reações) dentro de um determinado contexto social. Nas palavras da própria autora, esse tipo de análise “...põe em evidência, que mais que simplesmente descrever, ele permite, através do trabalho sistemático, operacionalizado e quantificado, encaminhar interpretações" (Biasoli-Alves, 1998, citado por Romanelli, 1998, p. 148).

\section{Contexto e participantes}

As crianças que participaram deste projeto de pesquisa tinham entre 5 e 6 anos de idade e estavam matriculadas, no ano 2007, em sete diferentes centros de educação infantil de Rio do Sul, localizados no Alto Vale do Itajaí, no Estado de SC. Rio do Sul fica a cerca de 180 km de Florianópolis, e conta atualmente com uma população de aproximadamente 60.000 habitantes. É uma cidade universitária, comercial, colonizada por alemães e italianos, cuja maior atividade econômica era a agropecuária. Participaram 130 famílias, ou seja, pais, mães ou responsáveis das crianças da amostra. Foram entrevistados 130 pais e avaliadas 130 crianças, sendo que 63 eram meninas e 67 meninos.

\section{Instrumentos}

Questionário sociodemográfico aplicado com os pais das crianças selecionadas para a amostra.

\section{Inventário de recursos do ambiente familiar} (RAF), que é um roteiro que se aplica sob forma de entrevista semi-estruturada em que cada tópico é apresentado à mãe/informante oralmente (Marturano, 2006). É composto por 10 tópicos, baseados nas descrições de recursos disponíveis no ambiente familiar, mediante levantamento em relatos de entrevistas conduzidas principalmente com mães ou com cuidadores de 70 crianças com queixa escolar. Santos (1999, citado por Marturano, 2006), em um estudo sobre a fidedignidade do RAF, entrevistou três mães com intervalos de 20 dias, e os resultados obtidos foram de 100\%, 99\% e 92\% de estabilidade, por meio do procedimento teste-reteste.

Teste de Prontidão Escolar Lollipop: tradução:Pirulito. TESTE DE AVALIAÇÃO DIAGNÓSTICA DE PRONTIDÃO ESCOLARREVISADO (Chew, A. L., 1981). Comportando 52 questões divididas em 4 subtestes, o Lollipop avalia a identificação das habilidades da criança nas seguintes áreas: matemática (identificação de números e contagem), português (identificação de letras e escrita), identificação de cores, formas e formas copiadas, descrição de figuras, posição e reconhecimento espacial. A pontuação total do teste é de 69 pontos. 


\section{Procedimentos}

Inicialmente, foi solicitada à Secretaria de Educação do Município de Rio do Sul a autorização para a realização da pesquisa. Em seguida, foi realizada uma reunião na própria secretaria com as diretoras dos centros de educação infantil que abrigam o maior número de crianças na faixa etária pretendida, para apresentação do projeto. Após aprovação da direção, foram entregues às diretoras cartas-convite, com questionário socio- demográfico, sendo que estes foram enviados para os pais através da escola, com a hora e data para aplicação do RAF, que teve lugar nas dependências da Escola.

O referido teste foi realizado com os pais das crianças individualmente, com hora marcada por eles, e agendada com a diretora do respectivo estabelecimento de ensino. No dia da aplicação do teste, os pais traziam o questionário sociodemográfico já preenchido. Antes da aplicação do RAF, foi lido, pela pesquisadora, o Termo de Consentimento Livre Esclarecido (TCLE), que foi assinado pelos pais/mães ou responsáveis pela criança. O teste era lido pela pesquisadora, e os pais respondiam conforme o seu ambiente familiar. Após assinatura do TCLE pelos pais e mães ou responsáveis, foi marcada com os professores a data para a aplicação do Lollipop com as crianças, na própria escola.

\section{Análise de dados}

Os dados foram analisados através do programa de computador denominado SPSS (pacote estatístico para as ciências sociais), versão 15, quando foram realizadas análises estatísticas descritivas e análises de associação entre as variáveis apresentadas. A análise é estatística descritiva, pois comporta média e desvio padrão para as questões que envolvem o inventário RAF assim como para os resultados do Lollipop.

Os dados foram testados com Teste t-Student para verificação das diferenças entre os grupos com resultados acima da média e abaixo da média de prontidão escolar. Os resultados de prontidão escolar foram avaliados com o Teste de Correlação $r$ de Pearson para verificar possíveis relações entre as variáveis discriminadas no estudo, considerando-se $p \leq 0,05$.

A variável independente suporte parental se divide em quatro domínios (Marturano, 2006), a saber:

\begin{tabular}{|c|c|}
\hline Domínios & Definição \\
\hline Atividades engajadas & $\begin{array}{l}\text { Atividades que pais e mães realizam com os filhos, como passeios, viagens, } \\
\text { assistir à TV, brincar, ler livros, ir ao cinema, circo, clube, parque de diversões. } \\
\text { A pontuação máxima desse domínio era de } 45 \text { pontos. }\end{array}$ \\
\hline Estímulos disponíveis & $\begin{array}{l}\text { São os recursos materiais existentes no ambiente familiar, como brinquedos, } \\
\text { livros e revistas. A família poderia pontuar até } 33 \text { pontos nesse domínio. }\end{array}$ \\
\hline $\begin{array}{l}\text { Práticas parentais que } \\
\text { promovem ligação } \\
\text { família e escola }\end{array}$ & $\begin{array}{l}\text { É a participação direta dos pais na vida escolar dos filhos, como comparecer às } \\
\text { reuniões da escola, supervisionar as lições de casa, verificar se o material está } \\
\text { em ordem, acompanhar as notas e a freqüência às aulas e avisar quando é hora } \\
\text { de ir para a escola. Esse domínio apresenta } 18 \text { pontos como pontuação máxima. }\end{array}$ \\
\hline Atividades previsíveis & $\begin{array}{l}\text { São as atividades que os pais e mães determinam aos filhos, como hora certa } \\
\text { para almoçar, tomar banho, brincar, ir dormir, levantar-se de manhã, jantar, } \\
\text { fazer a lição de casa e assistir à TV. São também as atividades diárias que } \\
\text { costumam reunir toda a família, como café da manhã, almoço, jantar, assistir à TV à } \\
\text { noite e finais de semana. A família poderia pontuar até } 28 \text { pontos nesse domínio. }\end{array}$ \\
\hline
\end{tabular}

Quadro 1. Domínios do suporte parental e suas definições. 
Já a variável dependente prontidão escolar se divide nos seguintes domínios:
Domínios
Definição

Identificação de cores e formas e formas copiadas

Descrição de figuras, posição e reconhecimento espacial

Identificação de números e contagem

Identificação de letras e escrita
Avalia a capacidade de a criança identificar seis tipos de cores, seis formas geométricas e copiar três destas (círculo, quadrado e cruz). A pontuação máxima para esse domínio é de 17 pontos.

Avalia a capacidade de a criança descrever uma figura (de uma gata com filhotes) e de identificar a posição dos filhotes (acima, embaixo, dentro, lado esquerdo, direito). Identificação das noções de maior, menor, primeiro, último e do meio, sendo sua pontuação máxima 17 pontos.

Identificação de números mostrados e contagem dos pirulitos que estão em quatro caixas diferentes. A pontuação máxima desse subteste é de 17 pontos.

A criança identifica as letras mostradas, e depois escreve o seu nome e as letras "A, B e C". A criança poderia pontuar 18 pontos nesse subteste.

Quadro 2. Domínios da prontidão escolar e suas definições.

Na Tabela 1, a média geral de prontidão escolar das crianças $(\mathrm{N}=130)$ foi de 47,59, e a de suporte parental nas famílias foi de 77,28. Considera-se que o desvio-padrão para a prontidão seja bastante alto $(14,57)$, porém esse desvio não modifica a curva normal em simetria, sendo possível avaliar os dados com testes paramétricos.

Tabela 1. Média do total de prontidão escolar e do total de suporte parental.

\begin{tabular}{lccccc}
\hline & N & Mínimo & Máximo & Média & Desvio Padrão \\
\hline Total Prontidão Escolar & 130 & 8 & 66 & 47,59 & 14,577 \\
Total Suporte Parental & 130 & 51 & 101 & 77,28 & 9,569 \\
\hline
\end{tabular}

O escore mínimo alcançado pelas crianças avaliadas no Teste de Prontidão Escolar foi de 8 pontos, e o escore máximo foi de 66 pontos, sendo que o total máximo no teste é de 69 pontos. Faz-se importante lembrar que a média do total de prontidão escolar $(47,59)$ foi considerada compatível com a média de crianças da mesma faixa etária do norte do Brasil e do Canadá (Dessen \& Szelbracikowski, 2004; Venet, Normandeau, Letarte, \& Bigras, 2003).

Na Tabela 2, percebe-se a correlação entre dois dos domínios do suporte parental, ou seja, atividades engajadas e estímulos disponíveis, em relação ao total de prontidão escolar.

Tabela 2. Intercorrelações ( $r$ de Pearson) entre os domínios do suporte parental e o total de prontidão escolar.

\begin{tabular}{lcc}
\hline & Estímulos disponíveis & Total de prontidão escolar \\
\hline Atividades engajadas &, $490\left(^{* *}\right)$ &, $223\left(^{*}\right)$ \\
Estímulos disponíveis &, $251\left(^{* *}\right)$ \\
Atividades previsíveis &,$- 224\left({ }^{*}\right)$ \\
$* * \mathrm{p} \leq 0,01$ & \\
$* \mathrm{p} \leq 0,05$. &
\end{tabular}


Pode-se dizer que pais e mães que proporcionaram suporte parental adequado, mais especificamente aquelas que se envolveram mais com os filhos em atividades programadas, regulares, ou que ofereceram estímulos como brinquedos ou livros apresentaram filhos com maior prontidão escolar. Houve também correlação entre os domínios atividades engajadas e estímulos disponíveis, o que significa que, quanto mais estímulos existem nesse ambiente, mais os pais se engajam em atividades com os filhos.

Observa-se, na Tabela 3, uma correlação com nível de significância importante, p<0,01, com a variável número de filhos e com os domínios e o total da prontidão escolar.

Tabela 3. Intercorrelações ( $r$ de Pearson) entre as variáveis sociodemográficas e os domínios de prontidão escolar.

\begin{tabular}{|c|c|c|c|c|}
\hline & Número de filhos & $\begin{array}{l}\text { Identificação números, } \\
\text { contagem }\end{array}$ & $\begin{array}{l}\text { Identificação } \\
\text { letras e escrita }\end{array}$ & $\begin{array}{l}\text { Total prontidão } \\
\text { escolar }\end{array}$ \\
\hline Idade do pai & & &,$- 265(* *)$ &,$- 217\left(^{*}\right)$ \\
\hline Escolaridade do pai &,$- 270(* *)$ & & & \\
\hline Escolaridade da mãe &,$- 233(* *)$ &, $198\left(^{*}\right)$ & &, $178\left(^{*}\right)$ \\
\hline Renda mensal & &, $224\left(^{*}\right)$ & &, $177\left(^{*}\right)$ \\
\hline Número de filhos & &,$- 454(* *)$ &,$- 434(* *)$ &,$- 466(* *)$ \\
\hline
\end{tabular}

Dos domínios avaliados pelo teste de prontidão, o domínio "identificação de números e contagem" correlacionou-se positivamente com a escolaridade da mãe e a renda mensal, o que demonstra uma tendência do grupo total a ter mais facilidade na identificação de números e na contagem quando a escolaridade da mãe e a renda mensal são maiores.

De acordo com a Tabela 4, das variáveis sociodemográficas, somente a idade do pai e o número de filhos apresentam correlações com suporte parental.

Tabela 4. Intercorrelações ( $r$ de Pearson) entre as variáveis sociodemográficas e os domínios e o total de suporte parental.

\begin{tabular}{lcccc}
\hline & Número de filhos & $\begin{array}{c}\text { Atividades } \\
\text { engajadas }\end{array}$ & $\begin{array}{c}\text { Atividades } \\
\text { previsíveis }\end{array}$ & $\begin{array}{c}\text { Total suporte } \\
\text { parental }\end{array}$ \\
\hline Idade do pai &, $\left.515^{* *}\right)$ &,$- 327\left(^{* *}\right)$ &,$- 241\left(^{*}\right)$ &,$\left.- 433^{* *}\right)$ \\
Número de filhos & &,$\left.- 316^{* *}\right)$ & &,$- 264\left(^{* *}\right)$ \\
\hline
\end{tabular}

** $p \leq 0,01$

$* p \leq 0,05$.

Todas as correlações com os domínios (atividades engajadas, estímulos disponíveis e atividades previsíveis) e com o total de suporte parental foram negativas. Isso significa que os pais mais jovens apresentaram-se mais capazes de fornecer suporte parental aos filhos no que se refere à qualidade e à quantidade de tempo com as crianças. 
De acordo com a Tabela 5, constatou-se que não há diferença entre os grupos de crianças com escores abaixo e acima da média de prontidão escolar em relação ao nível de escolaridade do pai, da mãe e a renda mensal.

Tabela 5. Resultados da comparação entre os grupos abaixo e acima da média de prontidão escolar em relação à escolaridade do pai, à escolaridade da mãe e à renda (Teste t-Student).

\begin{tabular}{lcccccccc}
\hline & $\begin{array}{c}\text { Prontidão escolar } \\
\text { abaixo e acima } \\
\text { da média }\end{array}$ & $\mathrm{N}$ & Média & Desvio-padrão & $\mathrm{F}$ & $\mathrm{GL}$ & $\mathrm{t}$ \\
\hline Escolaridade da mãe & $>47$ & 76 & 2,62 & 1,233 & & \\
Escolaridade do pai & $<47$ & 50 & 2,32 & 1,285 &, 645 & 124 & 1,307 \\
Renda mensal & $>47$ & 65 & 2,52 & 1,174 & & & \\
& $<47$ & 43 & 2,26 & 1,236 & 158 & 106 & 1,134 \\
& $>47$ & 73 & 3,37 & 1,173 & & & \\
& $<47$ & 50 & 3,44 & 1,232 &, 963 & 121 &,- 319 \\
\hline
\end{tabular}

Entretanto, retornando à Tabela 3, verifica-se que a escolaridade da mãe correlacionou-se significativamente e de forma positiva com a prontidão escolar, isto é, a prontidão escolar das crianças tende a aumentar na mesma proporção que a escolaridade das mães.

Já as diferenças entre o grupo abaixo e acima da média de prontidão em relação aos domínios de suporte parental mostraram-se significativas do ponto de vista estatístico, conforme a Tabela 6.

Tabela 6. Comparação entre os grupos prontidão escolar abaixo e acima da média em relação aos domínios do suporte parental (Teste t-Student).

\begin{tabular}{lcccccccc}
\hline & $\begin{array}{c}\text { Prontidão escolar } \\
\text { abaixo e acima } \\
\text { da média }\end{array}$ & $\mathrm{N}$ & Média & Desvio-padrão & $\mathrm{F}$ & $\mathrm{GL}$ & $\mathrm{t}$ \\
\hline Atividades engajadas & $>47$ & 78 & 23,54 & 3,617 & & & \\
& $<47$ & 52 & 21,52 & 5,066 & & 128 & $2,651\left(^{*}\right)$ \\
Estímulos disponíveis & $>47$ & 78 & 22,53 & 3,755 & & & \\
& $<47$ & 52 & 20,19 & 4,963 &, 854 & 128 & $3,047\left(^{*}\right)$ \\
$* * \mathrm{p} \leq 0,01$ & & & & & & & \\
\hline
\end{tabular}

Isso indica que o grupo de crianças com prontidão escolar acima da média apresenta uma diferença significativa em relação às crianças com prontidão abaixo da média tanto no que se refere aos estímulos disponíveis no ambiente familiar como às atividades engajadas entre pais e filhos.

\section{Discussão e conclusões}

Os dados referentes ao suporte parental e à prontidão escolar foram coletados através de instrumentos ainda pouco utilizados no Brasil. O Teste Lollipop (Chew, 1981), empregado para verificar a prontidão escolar das crianças, é uma novidade no sul do País, tendo sido aplicado em pesquisas apenas por Andrada (2007). Também o uso do RAF (inventário de recursos do ambiente familiar) é uma novidade em Santa Catarina, pois não há registros de pesquisas com esse inventário. Há, portanto, poucas pesquisas no Brasil que visam a identificar a prontidão escolar e que procuram relacioná-la com variáveis do microssistema familiar; nesse âmbito, destacam-se as pesquisas de Bigras e Dessen 
Conforme os

autores Andrade et

al. e Sameroff

(2005 e 1996,

citados por

Mengel, 2007),

Normandeau,

Letarte, Parent,

Bigras e Capuano

e Bigras, Morasse,

Gauthier e

Capuano, (1998, citados por

Andrada, 2007), a escolaridade

da mãe pode influenciar

diretamente o

desenvolvimento

global e específico da criança como fator de proteção.
(2002), de Dessen e Szelbracikowski (2004) e de Andrada (2007). Em relação ao RAF, não há relatos de pesquisas que relacionem dados coletados com o inventário e a prontidão escolar das crianças.

Sendo objetivo da pesquisa identificar os fatores de risco e de proteção no ambiente familiar, a fim de minimizar em futuras intervenções os impactos causados pelos riscos, foram considerados fatores de proteção o suporte parental, a idade do pai, a escolaridade da mãe e a renda mensal. Houve uma diferença significativa entre os grupos de prontidão abaixo e acima da média em relação à variável suporte familiar, e houve também uma correlação positiva importante entre os domínios atividades engajadas e estímulos disponíveis, contemplados pela variável independente - suporte parental - em relação à variável dependente - prontidão escolar.

Tais resultados confirmam os resultados de pesquisas anteriores, como as de D'Avila-Bacarji et al. (2005a, 2005b), Ferreira e Marturano (2002), Marturano (2006), Okano et al. (2004), as quais afirmam que o sucesso alcançado inicialmente pela criança na escola se deve às interações "pais-criança", ou seja, ao ambiente de suporte à aprendizagem desenvolvido no lar. De acordo com os pesquisadores Carlton e Winsler (1999), tais características referentes ao relacionamento "pais-criança" equipam a criança para que elas obtenham sucesso e tenham prontidão escolar.

No que se refere à correlação negativa existente entre o domínio do suporte parental denominado atividades previsíveis e o total da prontidão escolar, embora à primeira vista pareça ir contra as hipóteses da pesquisa, na pesquisa de Ferriolli (2005, citado por Marturano, 2006) com famílias cadastradas no Programa de Saúde da Família, as rotinas com horário definido apareceram como um fator de proteção frente ao risco de transtornos emocionais ou de comportamento; no entanto, tais medidas de atividades previsíveis que sinalizam algum grau de estabilidade na vida familiar costumam não mostrar associação com o desempenho escolar, como foi verificado aqui nesta pesquisa.

Esses resultados poderiam ser um argumento contra a manutenção dos tópicos referentes a rotinas e reuniões da família no teste de recursos do ambiente familiar, mas parece importante manter esses tópicos para detectar os lares caóticos, nos quais a desorganização da vida cotidiana pode afetar indiretamente o rendimento acadêmico, por interferir, por exemplo, na saúde emocional da criança.

Conforme os autores Andrade et al. e Sameroff (2005 e 1996, citados por Mengel, 2007), Normandeau, Letarte, Parent, Bigras e Capuano e Bigras, Morasse, Gauthier e Capuano, (1998, citados por Andrada, 2007), a escolaridade da mãe pode influenciar diretamente o desenvolvimento global e específico da criança como fator de proteção. Embora os resultados obtidos através da pesquisa de Andrada (2007) tenham demonstrado que a escolaridade do pai em Rio do Sul se correlacionou positivamente com a prontidão escolar de forma significativa, as mães desta pesquisa demonstraram ser mais escolarizadas que os pais, e isso justifica, em parte, o fato de só as mães apresentarem correlação com a prontidão escolar. Mães com mais anos de estudo se envolvem mais com a escolaridade dos filhos, e esse maior envolvimento está associado a um melhor desempenho da criança (D'Avila-Bacarji, Elias \& Marturano, 2005). No entanto, o grau de escolaridade dos dois cuidadores (pais e mães) demonstrou ser bastante significativo para a qualidade do suporte parental; dessa forma, a escolaridade do pai influencia indiretamente na prontidão escolar das crianças, visto que os domínios atividades engajadas e estímulos disponíveis do suporte parental se correlacionaram com o total de prontidão escolar.

Verificou-se que as crianças com os escores mais altos de prontidão tinham pais mais jovens e, além disso, pais mais jovens mostraram correlacionar-se positivamente com o total de suporte parental $(p \leq 0,01)$, ou seja, tendem 
a oferecer mais suporte parental aos filhos ao envolverem-se em atividades, realizarem passeios e viagens, além de proporcionarem mais estímulos como brinquedos e livros aos filhos, o que representa um fator de proteção para a prontidão escolar. Dessa forma, a idade dos pais pode representar um fator de risco para a prontidão escolar, pois pais mais velhos parecem menos disponíveis a oferecer um suporte parental mais adequado, ou seja, há pouco envolvimento e menos oferta de materiais estimuladores para o desenvolvimento das crianças por parte dos pais mais velhos em atividades compartilhadas com os filhos.

A variável quantidade de filhos, além de se correlacionar negativamente com os domínios identificação de números e contagem, identificação de cores e escrita e com o total de prontidão escolar, também demonstrou correlação negativa com as variáveis: escolaridade do pai e da mãe. Isso significa que a prontidão escolar das crianças tende a ser maior em famílias com menor número de filhos, e os pais e mães com mais anos de estudo tendem a ter menos filhos.

Os resultados sugerem que o grupo de prontidão escolar abaixo da média tem, no seu ambiente familiar, mais fatores de riscos, seja pela presença de situações adversas como, por exemplo, famílias com maior número de filhos e/ou pais com idade mais avançada, seja pela ausência de suporte parental eficaz à aprendizagem. Verificou-se então que famílias numerosas $(p \leq 0,01)$ representam um fator de risco para a qualidade do ambiente familiar, pois tendem a oferecer menos suporte parental. Esse resultado está de acordo com a pesquisa de Mengel (2007), na qual a alta densidade habitacional estava associada ao baixo desempenho cognitivo.

Esse dado é encontrado em pesquisas que mediram os fatores de risco que afetam o QI (quociente de inteligência), e, segundo algumas pesquisas de Sameroff, Seifer, Barocas, Zax e Greenspan (1987, citados por Sapienza \& Pedromônico, 2005), encontram-se o status socioeconômico, o tamanho da família e o suporte familiar; destes, puderam ser comprovados o tamanho da família e o suporte familiar, de acordo com as Tabelas 3 e 6, respectivamente, sendo considerado fator de risco para a prontidão escolar o alto número de filhos e o suporte parental ineficaz.

O status socioeconômico não pôde ser considerado um fator de risco para essas famílias, apesar de os resultados revelarem que a maioria das famílias viviam em situação de baixa renda mensal, pois não houve diferença significativa entre os grupos de crianças com escores de prontidão abaixo e acima da média em relação à renda mensal. No entanto, houve uma correlação positiva com nível de significância igual a $p \leq 0,05$ entre a renda mensal e o total de prontidão escolar, ou seja, conforme a renda mensal aumenta, a prontidão escolar também tende a aumentar. Isso pode ocorrer devido à presença ou não de recursos materiais que poderão atuar diretamente no desenvolvimento cognitivo da criança. Segundo o modelo ecológico do desenvolvimento humano de Bronfenbrenner (1996, citado por Mengel, 2007), a variável distal renda familiar pode influenciar as variáveis proximais de interrelações no ambiente familiar e, assim, o próprio desenvolvimento da criança.

Finalizando, em relação aos efeitos cumulativos de variáveis contextuais para a prontidão escolar, foram encontrados indicadores consistentes de fatores de risco no grupo de prontidão abaixo da média: os escores totais dos dois instrumentos utilizados para avaliar o nível de prontidão escolar e de suporte parental se correlacionaram negativamente e significativamente com as variáveis: número de filhos $(\mathrm{p} \leq 0,01)$ e idade do pai $(p \leq 0,05)$, ou seja, famílias com maior número de filhos e pais mais velhos tendem a oferecer menos suporte parental, apresentando filhos com menor prontidão escolar; da mesma forma, mostraram diferença significativa entre os grupos de prontidão escolar e de suporte parental abaixo e acima da média em relação às mesmas variáveis: número de filhos e idade do pai. 


\section{Edla Grisard Caldeira de Andrada *}

Doutora em Psicologia pelo Programa de Pós-graduação em Psicologia da Universidade Federal de Santa Catarina/ Apoio CAPES

Professora de Psicologia da Universidade para o Desenvolvimento do Alto Vale do Itajaí (UNIDAVI)

Psicóloga Clínica, especialista em Famílias

\section{Bárbara dos Santos Rezena}

Universidade para o Desenvolvimento do Alto Vale do Itajaí

Aluna do Curso de Psicologia - 10 $\underline{\text { a Fase }}$

\section{Gabriela Beling de Carvalho}

Universidade para o Desenvolvimento do Alto Vale do Itajaí

Aluna do Curso de Psicologia - 10 $\underline{\text { a Fase }}$

\section{Idonézia Collodel Benetti}

Universidade para o Desenvolvimento do Alto Vale do Itajaí

Aluna do Curso de Psicologia $-10^{\underline{a}}$ Fase

\section{* Endereço para envio de correspondência:}

Ed. Comercial: Rua Dr. Guilherme Gemballa, 13 Rio do Sul, SC CEP 8916-0000

E-mail: edla@matrix.com.br

Recebido 13/03/2008 Reformulado 23/07/2008 Aprovado 25/07/2008

\section{Referências}

Andrada, E. G. C. (2007). O treinamento de suporte parental (TSP) como fator de promoção do suporte parental e do desempenho escolar em crianças da primeira série. Tese de Doutorado, Programa de Pós-Graduação em Psicologia, Universidade Federal de Santa Catarina, Florianópolis.

Biasoli-Alves, Z. M. M. (1998). A pesquisa em psicologia - análise de métodos e estratégias na construção de um conhecimento que se pretende científico. In G. Romanelli, Diálogos metodológicos sobre prática de pesquisa (pp. 135-157). Ribeirão Preto, SP: Legis Summa.

Bigras, M., \& Dessen, M. D. (2002). Social competence in Brazilian preschoolers. Early Education \& Development, 13, 139-151.

Bronfenbrenner, U. (2002). Ecologia do desenvolvimento humano: experimentos naturais e planejados. Porto Alegre: Artmed.

Bronfenbrenner, U. (2005). Ecologia do desenvolvimento humano: experimentos naturais e planejados. Porto Alegre: Artmed.

Carlton, M. P., \& Winsler, A. (1999). School readness: The need for a paradigm shift. School Psychology Review, 28(3), 338 - 352.

Chew, A. L. (1981). The Lollipop Test: A diagnostic screening test of school readiness. Atlanta, GA: Humanics.

D’Avila-Bacarji, K. M. G., Marturano, E. M., \& Elias, L. C. S. (2005a). Suporte parental: umestudo sobre crianças com queixas escolares. Psicologia em Estudo, 10(1), 107-115.

D`Avila-Bacarii, K. M. G., Marturano, E. M., \& Elias, L. C. S. (2005b). Recursos e adversidades no ambiente familiar de crianças com desempenho escolar pobre. Paidéia: Cadernos de Psicologia e Educação, 15(30), 43-55.

Dessen, M. A., \& Szelbracikowski, A. C. (2004). Crianças com problemas de comportamento exteriorizado e a dinâmica familiar. Interação em Psicologia, 8(2), 171-180.

Ferreira, M. C. T., \& Marturano, E. M. (2002). Ambiente familiar e os problemas do comportamento apresentados por crianças com baixo desempenho escolar. Psicologia: Reflexão e Crítica, 15(1), 35-44.
Instituto Nacional de Estudos e Pesquisas Educacionais Anísio Teixeira. (2007). Censo escolar 2006. Recuperado em 20 de março de 2007, de www.inep.gov.br/

Marturano, E. M. (2006). O inventário de recursos do ambiente familiar. Psicologia: Reflexão e Crítica, 19(3), 498-506.

Meisels, S. J. (1999). Assessing readiness. In R. C. Pianta \& M. J. Cox (Eds.), The transition to kindergarten (pp. 39-66). Baltimore: Paul Brookes.

Mengel, M. R. S. M. (2007). Vigilância do desenvolvimento em programa de saúde da família: triagem para detecção de riscos para problemas de desenvolvimento. Tese de Doutorado, Faculdade de Medicina, Universidade de São Paulo, Ribeirão Preto, SP. Recuperado em 1 de novembro de 2007, de http://www.teses.usp.br/teses/disponiveis/17/17148/tde02092007-204350/DOUTORADO_MARGARET_ROSE_ SANTA MARIA MENGEL.pdf

Okano, C. B., Loureiro, S. R., Linhares, M. B. M., \& Marturano, E. M. (2004). Crianças com dificuldades escolares atendidas em programa de suporte psicopedagógico na escola: avaliação do autoconceito. Psicologia: Reflexão e Crítica, 17(1), 121-128.

Parker, F. L., Boak, A. Y., Griffin, K. W., Ripple, C., \& Peavy, L. (1999). Parent-relationship, home learning environment, and school readness. School Psychology Review, 28(3), 413-425.

Pianta, R. C., \& Walsh, D. J. (1996). High-risk children in schools: Constructing sustaining relationships. New York: Routledge.

Sapienza, G., \& Pedromônico, M. R. M. (2005). Risco, proteção e resiliência no desenvolvimento da criança e do adolescente. Psicologia em Estudo, 10(2), 209 - 216.

Venet, M., Normandeau, S., Letarte, M. J., \& Bigras, M. (2003). Les propriétés psychométriques du Lollipop (mesure et évaluation). Revue de Psychoéducation, 32(1), 165-176. 